\title{
Mechanistic Insight Into Cadmium- and Zinc-Induced Inactivation of the Candida albicans Pif1 Helicase
}

\author{
Bo Zhang ${ }^{1 * t}$, Qintao Zhang ${ }^{1+}$, Xinting Zhu ${ }^{1}$, Dayu $\mathrm{Li}^{1}$, Xiaolei Duan ${ }^{2}$, Jiao Jin ${ }^{1}$, Kejia Wang ${ }^{3}$, \\ Yan Xie ${ }^{4 *}$ and Yang Liu ${ }^{4 *}$ \\ ${ }^{1}$ College of Basic Medicine, Zunyi Medical University, Zunyi, China, ${ }^{2}$ Medical Laboratory, Affiliated Hospital of Zunyi Medical \\ University, Zunyi, China, ${ }^{3}$ College of Life Sciences, Guizhou University, Guiyang, China, ${ }^{4}$ School of Public Health, Zunyi Medical \\ University, Zunyi, China
}

\section{OPEN ACCESS}

Edited by:

Huiming Lu,

University of Texas Southwestern Medical Center, United States

Reviewed by: Qing Hu,

University of Texas Southwestern Medical Center, United States Mustafa Nazir Okur, University of California, Irvine, United States

*Correspondence: Yang Liu

yangliuzmu@163.com Yan Xie xie814yan@163.com Bo Zhang

bozhangzmu@163.com

${ }^{+}$These authors have contributed equally to this work and share first authorship

Specialty section:

This article was submitted to Protein Biochemistry for Basic and Applied Sciences,

a section of the journal

Frontiers in Molecular Biosciences

Received: 17 September 2021 Accepted: 03 December 2021 Published: 21 January 2022

Citation: Zhang B, Zhang Q, Zhu X, LiD, DuanX Jin J, Wang K, Xie $Y$ and Liu $Y(2022)$ Mechanistic Insight Into Cadmiumand Zinc-Induced Inactivation of the

Candida albicans Pif1 Helicase. Front. Mol. Biosci. 8:778647. doi: $10.3389 /$ fmolb.2021.778647
Zinc and cadmium are environmental contaminants that can cause disease by affecting the activity of DNA-repair proteins. In this study, we investigated the effect of $\mathrm{Zn}^{2+}$ and $\mathrm{Cd}^{2+}$ on the Candida albicans Pif1, a DNA-repair helicase that plays a critical role in ensuring genomic stability. We show that $\mathrm{Zn} 2+$ and $\mathrm{Cd} 2+$ strongly inhibit both the ATPase and the unwinding activities of CaPif1, but have no effect on its DNA binding activity. High concentrations of $\mathrm{Cd} 2+$ may bind to the cysteine residues of CaPif1, and its inhibition appears to be difficult to be restored by ethylene diamine tetraacetic acid, while inhibition due to $\mathrm{Zn}^{2+}$ can. When the two ions are at low concentrations, increasing the concentration of ATP in the reaction can appropriately weaken the inhibitory effect of $\mathrm{Zn}^{2+}$, while cysteine can reduce the inhibitory effect of $\mathrm{Cd}^{2+}$. In addition, we found that for both $\mathrm{Cd}^{2+}$ and $\mathrm{Zn}^{2+}$ the inhibition effects were nearly 100 times greater in reduced environments than in non-reducing environments. When heavy metals stimulate the body's response, the environment of the body becomes less reducing, and thus the tolerance of CaPif1 to heavy metals will be stronger. We propose that CaPif1 may resist the toxicity of heavy metals through this mechanism. Altogether, our results provide new insights into the mechanisms by which heavy metals are toxic to DNA-repair proteins.

Keywords: zinc, cadmium, CaPif1, ATPase, DTT, helicase, heavy metal, toxicity

\section{INTRODUCTION}

With the development of society, an increasing amount of heavy metals are released into the environment through industry and agriculture. Heavy metals tend to bioaccumulate, display biomagnification, and are toxic, which can lead to a variety of human diseases. They damage the kidneys, cause harm to the lungs upon inhalation, and interfere with bone metabolism (Maret and Moulis, 2013). Zinc's chemical and physical properties are similar to those of cadmium (Brzoska, 2001), but the biological effects of these two heavy metals are quite different. Zinc is required for biological functions (Andreini et al., 2004), as it protects genetic stability and is a key component of proteins functioning in the antioxidant mechanism and DNA repair (Yildiz et al., 2019). In contrast, it has been proven that cadmium causes cancer.

Previous studies have shown that cadmium is a weak denaturing agent. It does not directly cause obvious DNA damage and seems to operate indirectly, but the exact molecular mechanism is unclear (Waisberg et al., 2003). The principal mechanisms of cadmium carcinogenicity are 1) the inhibition of DNA repair (Hengstler et al., 2003); 2) the interference with the antioxidant defense system that 
stimulates the production of reactive oxygen species (ROS), which directly induce DNA damage through oxidizing nucleoside bases and indirectly affect DNA repair (Jomova and Valko, 2011; Srinivas et al., 2019); 3) the regulation of cellular signal transduction pathways (Waisberg et al., 2003). The first and second mechanisms are associated with DNA-repair proteins. Zinc can reduce cadmium toxicity, and increasing the zinc supply may reduce cadmium absorption and accumulation, thus preventing or reducing the adverse actions of cadmium, whereas zinc deficiency can intensify cadmium accumulation and toxicity (Brzoska MM 2001; Yu et al., 2021). Interestingly, zinc decreases cadmium toxicity is related to DNA repair. Zinc contributes to an efficient DNA repair system, thereby alleviating DNA damage. Furthermore, zinc can reduce oxidative stress in cells (Yildiz et al., 2019). Thus, the role of zinc and cadmium is closely linked to DNA-repair proteins.

Pif1, a DNA-repair protein with a zinc finger structure, has a helicase activity that plays a critical role in ensuring genomic stability by promoting mitochondrial DNA stability (Geronimo et al., 2018), regulating ribosomal DNA replication (Ivessa et al., 2000) and telomerase activity, among other roles (Boule et al., 2005). Pif1 is closely linked to cancer, and it affects the apoptosis of neuroblastoma cells and cervical cancer cells (Chen et al., 2020; Wang et al., 2020). On the whole, it is of great biological significance to study the toxic effects of heavy metals on Pif1.

Pif1 is found in almost all eukaryotes, and the Pif1 family is highly conserved from yeasts to humans (Futami et al., 2007). In this study, we investigated and characterized the biochemical activity and substrate specificity of Candida albicans Pif1 (CaPif1) and the impact of six heavy metal ions, manganese $\left(\mathrm{Mn}^{2+}\right)$, calcium $\left(\mathrm{Ca}^{2+}\right)$, zinc $\left(\mathrm{Zn}^{2+}\right)$, nickel $\left(\mathrm{Ni}^{2+}\right)$, copper $\left(\mathrm{Cu}^{2+}\right)$, and cadmium $\left(\mathrm{Cd}^{2+}\right)$, on its activity. We found that $\mathrm{Zn}^{2+}, \mathrm{Ni}^{2+}$, and $\mathrm{Cd}^{2+}$ strongly inhibited the unwinding activity of CaPif1, but had no obvious effect on its DNA binding activity. The inhibitory effects of $\mathrm{Zn}^{2+}$ and $\mathrm{Cd}^{2+}$ on CaPif1 were different, especially on its helicase functions: 1) it was difficult to restore the damage caused to CaPif1 in high concentrations of $\mathrm{Cd}^{2+}$ using ethylene diamine tetraacetic acid (EDTA), but not under $\mathrm{Zn}^{2+} ; 2$ ) the inhibitory effect of $\mathrm{Cd}^{2+}$ was more serious than that of $\mathrm{Zn}^{2+}$; 3) cysteine (Cys) could mitigate the damage caused by $\mathrm{Cd}^{2+}$, and ATP could alleviate the inhibition of $\mathrm{Zn}^{2+}$ in the low concentration range. Even more surprisingly, CaPif1 could effectively resist the inhibitory effects of these heavy metals in a low reducing environment. These findings provide a new understanding of the toxic molecular mechanisms of metal accumulation in organisms leading to a variety of human diseases.

\section{MATERIALS AND METHODS}

\section{Chemical Reagents}

$\mathrm{CdCl}_{2}, \mathrm{ZnCl}_{2}, \mathrm{MgCl}_{2}, \mathrm{MnSO}_{4}, \mathrm{CaCl}_{2}, \mathrm{NiSO}_{4}, \mathrm{CuSO}_{4}, \mathrm{EDTA}$, dithiothreitol (DTT), sodium dodecyl sulfate(SDS), nucleotide triphosphates (NTPs), and deoxynucleotide triphosphates (dNTPs) were purchased from Sangon Biotech (Shanghai) Co., Ltd. Amino acids, ATP Assay Kit was purchased from Beyotime Biotechnology (Shanghai, China).

\section{Recombinant Proteins}

The open reading frame encoding the CaPifl protein (NCBI number: AOW31431.1) was generated by PCR and cloned into a modified pET-21a vector with an N-terminal SUMO tag to generate His-SUMO-CaPifl. The construct was transformed into E. coli $\mathrm{C} 2566 \mathrm{H}$. The cells were grown in $\mathrm{LB}$ medium containing $100 \mu \mathrm{g} / \mathrm{ml}$ ampicillin at $37^{\circ} \mathrm{C}$ to an $\mathrm{OD}_{600}$ of 0.7 and induced with $0.3 \mathrm{mM}$ IPTG at $18^{\circ} \mathrm{C}$ for an additional $16 \mathrm{~h}$. The cells were then harvested by centrifugation, resuspended in a buffer [20 mM Tris- $\mathrm{HCl}$ ( $\mathrm{pH} 7.6), 500 \mathrm{mM} \mathrm{NaCl}$ ], and sonicated 2-3 times to shear their DNA. All purification steps were performed at $4^{\circ} \mathrm{C}$. After centrifugation and filtration using a $0.45 \mu \mathrm{m}$ membrane, the mix was applied to a HisTrap NiSepharose column (GE Healthcare) and eluted in a gradient increased to $200 \mathrm{mM}$ imidazole over 15 column volumes. The His-SUMO tag was removed by SUMO enzyme. The mixture of proteins was dialyzed overnight against $20 \mathrm{mM}$ Tris- $\mathrm{HCl}$ ( $\mathrm{pH} 7.6$ ), and $500 \mathrm{mM} \mathrm{NaCl}$, and applied to the second round of $\mathrm{Ni}$ sepharose chromatography. Finally, the purified protein fractions were concentrated to $10 \mathrm{mg} / \mathrm{ml}$. Glycerol was added at a final concentration of $15 \%$, and the proteins were stored at $-80^{\circ} \mathrm{C}$.

\section{Oligonucleotides}

All DNA substrates used in the experiment were PAGE-purified and purchased from GENEWIZ laboratory (Jiangsu, China). The sequences of unlabeled or fluorescently labeled DNA are shown in Table 1. All of the labeled DNA involved in the experiment was labeled with $3^{\prime}$-fluorescein ( $3^{\prime}$-FAM). Double-stranded DNA substrates were obtained by mixing equimolar concentrations of complementary single-stranded oligonucleotides in $50 \mathrm{mM}$ Tris- $\mathrm{HCl}(\mathrm{pH} 7.5)$ and $25 \mathrm{mM} \mathrm{NaCl}$. The mixture was heated to $95^{\circ} \mathrm{C}$ for $5 \mathrm{~min}$, and annealing was allowed by slow cooling to room temperature. Finally, series of duplex DNA samples were stored at $-40^{\circ} \mathrm{C}$.

\section{Annealing Assays}

To determine the annealing activity of CaPif1, we used two partially complementary single-stranded DNA (10 nM) samples mixed with different concentrations of CaPif1 in annealing buffer [25 mM Tris- $\mathrm{HCl}$ ( $\mathrm{pH}$ 7.5), $50 \mathrm{mM} \mathrm{NaCl}, 1.5 \mathrm{mM} \mathrm{MgCl}, 1 \mathrm{mM}$ DTT]. No ATP was used because DNA annealing is usually ATPindependent, while unwinding depends on ATP hydrolysis. If the solution contains ATP, the double-stranded DNA produced by annealing will be unwound, so that annealing cannot be observed.

After incubation at $30^{\circ} \mathrm{C}$ for $10 \mathrm{~min}$, adding $5 \times$ stop loading buffer (150 mM EDTA, 2\% SDS, 30\% glycerol, and $0.1 \%$ bromophenol blue) to stop the reaction. The samples were electrophoresed on a $12 \%$ native polyacrylamide gel and visualized with ChemiDoc MP (Bio-Rad, CA, United States).

\section{DNA Binding Assays}

Fluorescence polarization assay: The binding of CaPif1 to DNA was monitored by fluorescence polarization assay using the SpectraMax iD3 microplate reader (Molecular Devices, LLC, PA, United States). following previously reported methods (Zhang et al., 2016). Briefly, the fluorescence-labeled DNA substrate $(5 \mathrm{nM})$ was mixed with varying amounts of CaPif1 in binding buffer [ $25 \mathrm{mM}$ Tris- $\mathrm{HCl}(\mathrm{pH} 7.5), 50 \mathrm{mM} \mathrm{NaCl}, 1.5 \mathrm{mM}$ 
TABLE 1 | . Structures and sequences of the DNA substrates.

\begin{tabular}{|c|c|c|c|}
\hline Name & Structure & Sequence (F, fluorescein) & Comment \\
\hline S43 & ${ }^{5} \quad 43 \mathrm{nt}$ & 5'-CTGTAGGAATGTGAAATAAAAACGATGTITATTACATTGTA-3'-F & 43nt ssDNA \\
\hline S21 & $5^{\prime} \quad 21 \mathrm{nt} 3^{\prime}$ & 5'-TACAATGTAAATAAAACATCG-3' & $21 n t$ ssDNA \\
\hline S40 & ${ }^{5} \quad 40$ nt & 5'-CCATGCAGCTGTCAGTCCATTGTCATGCTAGGCCTACTGC-3'-F & 40nt ssDNA \\
\hline DS32 & 32 bp & $\begin{array}{l}\text { 5'-TATCGAAGAATGTTATGTCATTCCGGCAGATG-3'-F } \\
\text { 3'-ATAGCTTCTTACAATACAGTAAGGCCGTCTAC-5' }\end{array}$ & 32bp dsDNA \\
\hline OhS22D21 & & $\begin{array}{l}\text { 5'-CTGTAGGAATGTGAAATAAAAACGATGTITATITACATTGTA-3'-F } \\
3^{\prime} \text {-GCTACAAAATAAATGTAACAT-5' }\end{array}$ & $5^{\prime}$-22nt-Overhanged-21bp \\
\hline BS12 & & $\begin{array}{l}\text { 5'-CCATGCAGCTGTCAGTCCATTGTCATGCTAGGCCTACTGC-3'-F } \\
\text { 3'-GGTACGTCGACAGTGTCCATTGTCATCGATCCGGATGACG-5' }\end{array}$ & Bubble-12nt \\
\hline YS22 & & $\begin{array}{l}\text { 5'-CTGTAGGAATGTGAAATAAAAACGATGTाTATाTACATTGTA-3'-F } \\
3^{\prime} \text {-AAAAAAAAAAAAAAAAAAAAAAGCTACAAAATAAATGTAACAT-5' }\end{array}$ & Y-structure-22nt \\
\hline OhS4D20 & & $\begin{array}{l}\text { 5'-GCCCTGGTGCCGACAACGAAGGTA-3' -F } \\
\text { 3'-ACCACGGCTGTTGCTTCCAT-5' }\end{array}$ & 5'-4nt-Overhanged-20bp \\
\hline OhS12D20 & & $\begin{array}{l}\text { 5'-TATCGAAGAATGTTATGTCATTCC GGCAGATG-3'-F } \\
\text { 3'-AATACAGTAAGGCCGTCTAC-5' }\end{array}$ & $5^{\prime}-12$ nt-Overhanged-20bp \\
\hline OhS20D20 & & $\begin{array}{l}\text { 5'-CCATGCAGCTGTCAGTCCATTGTCATGCTAGGCCTACTGC-3'-F } \\
\text { 3'-ACAGTACGATCCGGATGACG-5' }\end{array}$ & 5'-20nt-Overhanged-20bp \\
\hline OhS12D12 & & $\begin{array}{l}\text { 5'-GCCCTGGTGCCGACAACGAAGGTA-3'-F } \\
\text { 3'-TGTTGCTTCCAT-5' }\end{array}$ & $5^{\prime}-12$ nt-Overhanged-12bp \\
\hline OhS12D28 & $\frac{5^{\prime}, 12 n t \quad 28 b p}{\frac{32}{10 p}}$ & $\begin{array}{l}\text { 5'-CCATGCAGCTGTCAGTCCATTGTCATGCTAGGCCTACTGC-3'-F } \\
\text { 3'-GTCAGGTAACAGTACGATCCGGATGACG-5' }\end{array}$ & $5^{\prime}-12$ nt-Overhanged-28bp \\
\hline
\end{tabular}

$\mathrm{MgCl}_{2}$, and $\left.1 \mathrm{mM} \mathrm{DTT}\right]$ at $25^{\circ} \mathrm{C}$ for $10 \mathrm{~min}$. Then, the fluorescence polarization was measured. The anisotropy value of each test point was averaged by three independent tests.

Electrophoretic mobility shift assay (EMSA): The $3^{\prime}$ fluorescein labeled DNA substrates $(10 \mathrm{nM})$ were preincubated with varying amounts of CaPif1 in binding buffer at $25^{\circ} \mathrm{C}$ for $5 \mathrm{~min}$. Before electrophoresis, $5 \times$ loading buffer $(60 \%$ glycerol and $0.1 \%$ bromophenol blue) was added into the mixture. The electrophoresis conditions were as follows: native PAGE (Acr:Bis = 39:1), 6\% polyacrylamide, $100 \mathrm{~V}, 40 \mathrm{~min}$. The results were visualized by a ChemiDoc MP Imaging System (BioRad, CA, United States).

\section{Helicase Assay}

CaPif1 was combined with duplex DNA in unwinding buffer [25 mM Tris $\mathrm{HCl}$ (pH 7.5), $50 \mathrm{mM} \mathrm{NaCl}, 1.5 \mathrm{mM} \mathrm{MgCl}_{2}, 1 \mathrm{mM}$ DTT, $5 \mathrm{mM} \mathrm{ATP}$ ], and ATP was added to initiate the reaction at $30^{\circ} \mathrm{C}$ for $10 \mathrm{~min}$. The reactions were quenched with the addition of $5 \times$ stop loading buffer. Products of DNA unwinding reactions were resolved on native PAGE 12\% (Acr:Bis = 39:1) gels, $100 \mathrm{~V}$,
$80 \mathrm{~min}$. DNA in polyacrylamide gels was visualized using a ChemiDoc MP and quantitated using the Image Lab software (Bio-Rad). The percentage of unwound helicase substrate was calculated using the following Eq. 1, where $\mathrm{P}$ is the product (ssDNA), and $\mathrm{S}$ is the substrate (dsDNA):

$$
\% \text { unwinding }=100 \% \times P /(S+P) \text {. }
$$

\section{ATPase Assay}

ATPase activity was detected using a commercial ATPase assay kit according to manufacturer's instructions (Beyotime Biotechnology, Shanghai, China). The wavelength was $540 \mathrm{~nm}$, and the cumulative detection time was $10 \mathrm{~s}$. The experiment was repeated three times and the percentage of ATP consumption was calculated using the following Eq. 2:

$$
\% \text { consumption }=(P-S) / P \times 100 \% \text {, }
$$

where $\mathrm{P}$ is the light value produced by the control group (without CaPif1), $\mathrm{S}$ is the light value produced by the experimental group (various CaPifl concentrations), and P-S is the light value reduced 


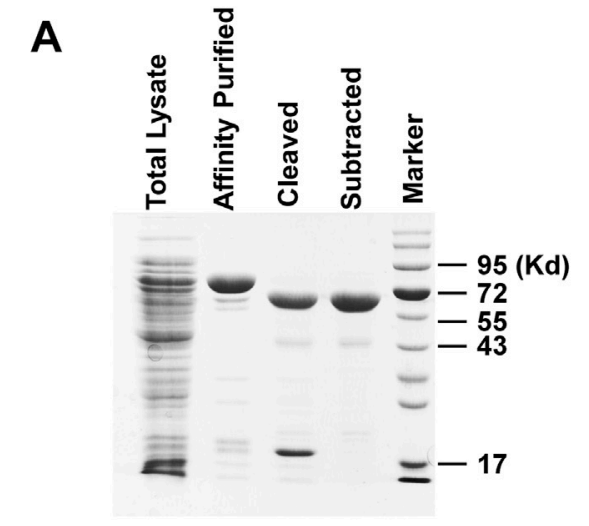

C

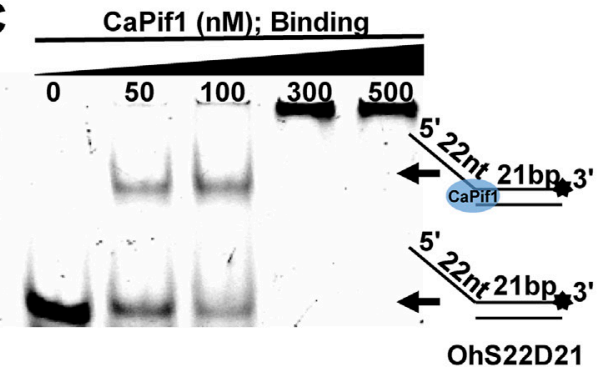

B

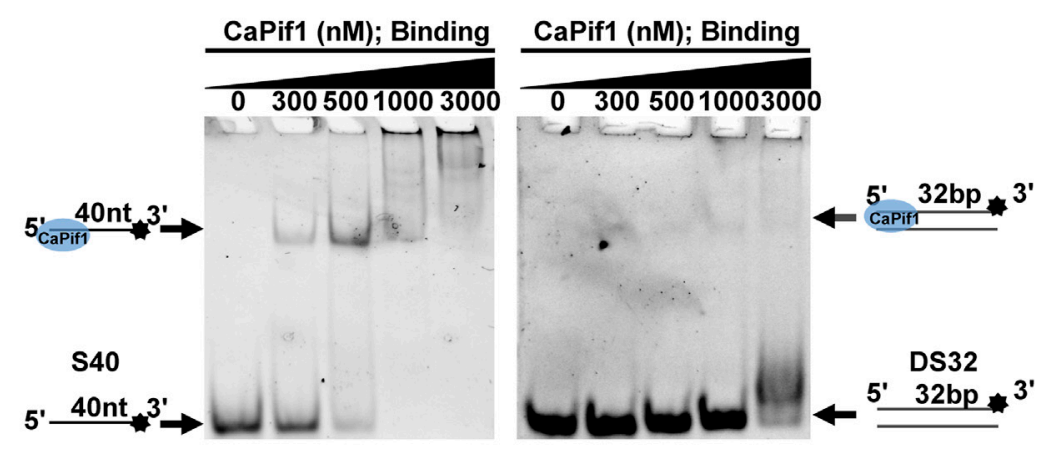

D

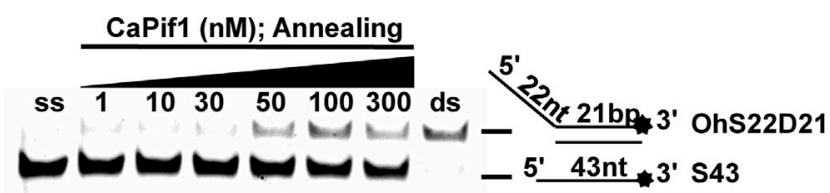

FIGURE 1 |Binding and annealing activity of purification of CaPif1. (A) SDS-10\% polyacrylamide gel stained with Coomassie brilliant blue dye. Lane marker: protein molecular mass markers (with masses, in kilodaltons, indicated on the right). (B-C) CaPif1 binding activity was detected by DNA of three substrates. Top of the arrow: CaPif1-DNA complexes; Bottom of the arrow: free DNA. Native PAGE (Acr: Bis = 39:1) 6\%, 100 V, 40 min. (D) Annealing activity of CaPif1. Native PAGE (Acr: Bis = 39:1) 12\%, 100 V, 80 min. Lane ds: OhS22D21; lane ss: S43 (see Methods for more details). The results of figures (B-D) were visualized by a ChemiDoc MP Imaging System (Bio-Rad, California, United States).

by the ATP consumption of the experimental group. Luminance was detected using the SpectraMax iD3 microplate reader (Molecular Devices, LLC, PA, United States). The fitting of the combined characteristic curve was done using the software ORIGIN.

\section{RESULTS}

\section{Characterization of the Basic Biochemical Activity of CaPif1}

We successfully expressed and obtained recombinant CaPif1 through HisTrap affinity purification and cutting and subtracting SUMO tags in order to dissect its physiological functions (Figure 1A). Previous studies have shown that helicase will bind to the nucleic acid substrate in advance before the unwinding process (Witkiewicz-Kucharczyk and Bal, 2006). Therefore, in order to test the binding activity of CaPif1 to the nucleic acid substrate, different structures of DNA were selected: ssDNA (S40), blunt end dsDNA (DS32), and $5^{\prime}$ - overhanged DNA (OhS22D21). We fixed three substrate concentrations at $10 \mathrm{nM}$, and CaPif1 at varying concentrations $(0-3,000 \mathrm{nM})$ in binding buffer (Materials and Methods). As the concentration of CaPif1 increased, free DNA (bottom arrow in Figures 1B,C) gradually decreased; in contrast, the protein-DNA complex (up arrow in Figures 1B,C) gradually increased. Through comparison, it was found that CaPif1 with blunt end dsDNA had very weak binding activity, while the other two substrates containing single-stranded tail structures showed high affinity. When CaPifl reached a certain high concentration, the protein-DNA complexes were found near the spot hole, indicating that the high concentration of CaPif1 may form dimer or polymer (Yu et al., 2021).

In addition, we tested whether CaPif1 had annealing activity (Figure 1D). Two partially complementary single-stranded oligonucleotides (S43 and S21 in Table 1, where S43 has been labeled with $3^{\prime}$-fluorescein) were incubated with different concentrations of CaPif1 (1-300 nM) in annealing buffer. As the concentration of CaPif1 increased, the annealed doublestranded DNA also increased. These results indicated that CaPifl was competent for promoting DNA annealing.

\section{CaPif1 Unwinds More Specific Structured DNA}

The helicase of the Pif1 family unwinds a broad range of DNA substrates, a common feature for DNA structures is the presence of a $5^{\prime}$-ss tail. To probe the possible physiological functions of CaPif1 in the cell, different structured DNAs were labeled fluorescent groups $\left(3^{\prime}\right.$-FAM) to determine unwinding activity by EMSA, as shown in the figure (Figures 2A-D). Among the various DNA substrates tested, there was a common feature. CaPif1 could effectively unwind the DNA structures containing the $5^{\prime}$-ss tail, such as $5^{\prime}$-overhang (OhS22D21) and forked 


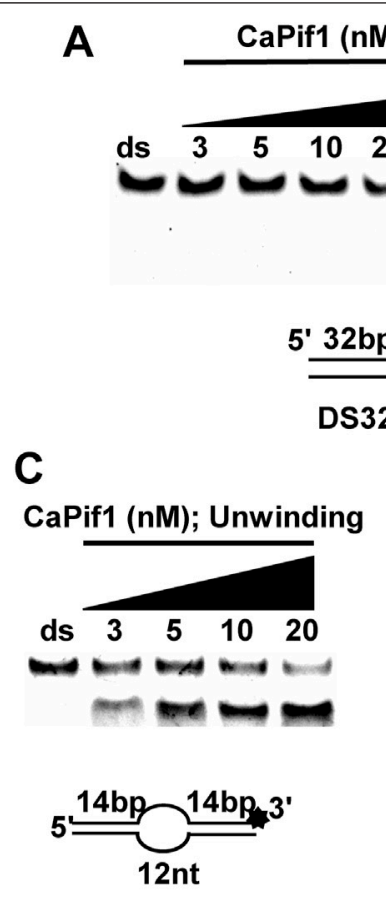

BS12
D

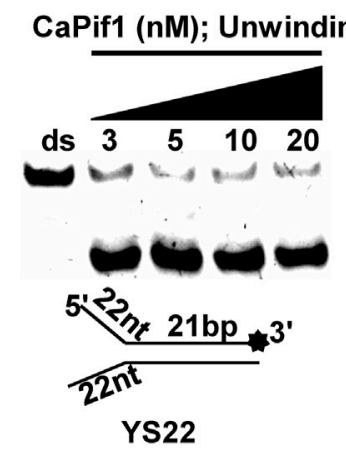

B CaPif1 (nM); Unwinding
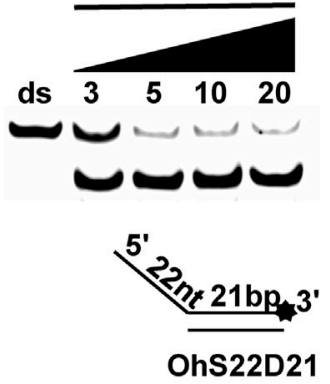

E

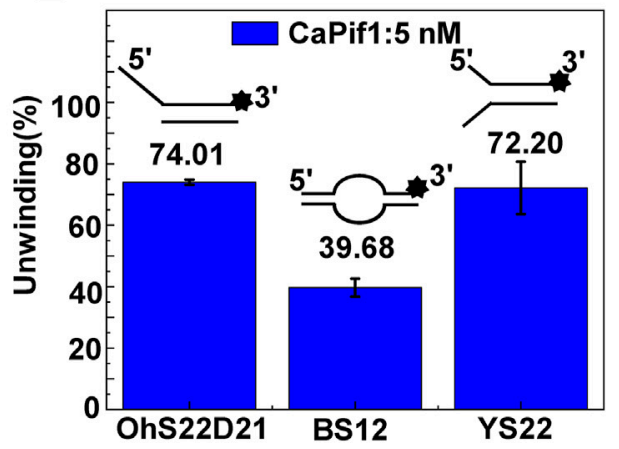

FIGURE 2 | Unwinding preference of CaPif1. Unwinding characteristics of CaPif1 using various DNA substrates: (A) blunt end dsDNA, (B) 5'-overhanged, (C) Bubble, (D) Y-structure. (A-D) The experiments were performed using a series of double-stranded DNA substrates (shown in Table 1), fixed at 10 nM, and CaPif1 gradually increased. The unwinding reaction was initiated by adding $5 \mathrm{mM}$ ATP at $30^{\circ} \mathrm{C}$ for $10 \mathrm{~min}$. Native PAGE (Acr: Bis = 39:1) $12 \%, 100 \mathrm{~V}, 80 \mathrm{~min}$. The fluorescence signals were visualized by a ChemiDoc MP Imaging System (Bio-Rad, California, United States). We calculated the proportion of unwinding DNA at 5 nM CaPif1 for a clearer analysis by scanning the gray values with Image Lab software (E) (Supplementary Table S1). All experiments were performed under standard experimental conditions as described in "Materials and Methods."

(YS22). Even at high concentrations $(100 \mathrm{nM})$ of CaPif1, the blunt end dsDNA (DS32) structure still was not unwound. To note, the property that CaPif1 unwinds more efficiently $5^{\prime}$-ss tail DNA than that of Bubble (BS12) structure. The unwinding ratios are compared in (Figure 2E; Supplementary Table S1), and the sequences of these substrates are summarized in Table $\mathbf{1 .}$

We further compared the effects of the $5^{\prime}$-ss tail and doublestrand length on unwinding activity. Two sets of experiments were designed: in one set the double-strands were kept at the same length but the length of the $5^{\prime}$-ss tail gradually increased (OhS4D20, OhS12D20, and OhS20D20) (Figure 3A), while in the other set the $5^{\prime}$-ss tail length was fixed, but the double-strand length gradually increased (OhS12D12, OhS12D20, and OhS12D28) (Figure 3B). The results showed that the unwinding ratio of CaPif1 gradually decreased with the increase of the double-strand length, and the unwinding ratio of $\mathrm{CaPif1}$ increased as the tail chain length increased (Figures 3C,D; Supplementary Table S2).

\section{A Preference for Adenosine Nucleotides of CaPif1}

Helicase can usually use the energy of hydrolyzing NTPs/ dNTPs to melt double-stranded DNA, but whether CaPif1 has a preference for adenosine nucleotides as an energy source. Under the same experimental conditions, the unwinding activity of CaPif1 was measured in the presence of different types of NTPs and dNTPs. The results showed that CaPif1 could efficiently unwind the DNA in the presence of ATP, dATP, CTP, and dCTP, and $80 \%$ of DNA was unwound at $100 \mu \mathrm{M}$ (Figures 4A,B). However, in the presence of GTP, dGTP, dTTP, UTP, and dUTP, less DNA was unwound. We found that when the concentration of these low-efficiency adenosine nucleotides was increased to $5 \mathrm{mM}$, the unwinding activity of CaPif1 was inhibited (Figures 4C-E). We speculate that for translocation helicases, the unwinding is dependent on the hydrolysis of NTPs or dNTPs, which depends on the ratio of NTPs/dNTPs to $\mathrm{Mg}^{2+}$ (Harmon and Kowalczykowski, 2001; Choudhary et al., 2004). Increasing the concentration of NTPs/dNTPs will disrupt the ratio and lead to hydrolysis inhibition, just as in NS3 helicase (Frick et al., 2007). These results indicate that CaPif1 can use the energy from the hydrolysis of a wide range of nucleotides to unwind DNA. We calculated the proportion of unwinding DNA at 100 and 5,000 $\mu \mathrm{M}$ NTP for a clearer analysis by scanning the gray values with Image Lab software (Figure 4F) (Supplementary Table S3).

\section{The Activity of CaPif1 is Affected by the Metal}

Helicases are usually fully and equally active for DNA unwinding in the presence of metal ions. $\mathrm{Mg}^{2+}$ and $\mathrm{Mn}^{2+}$ are common. Some 

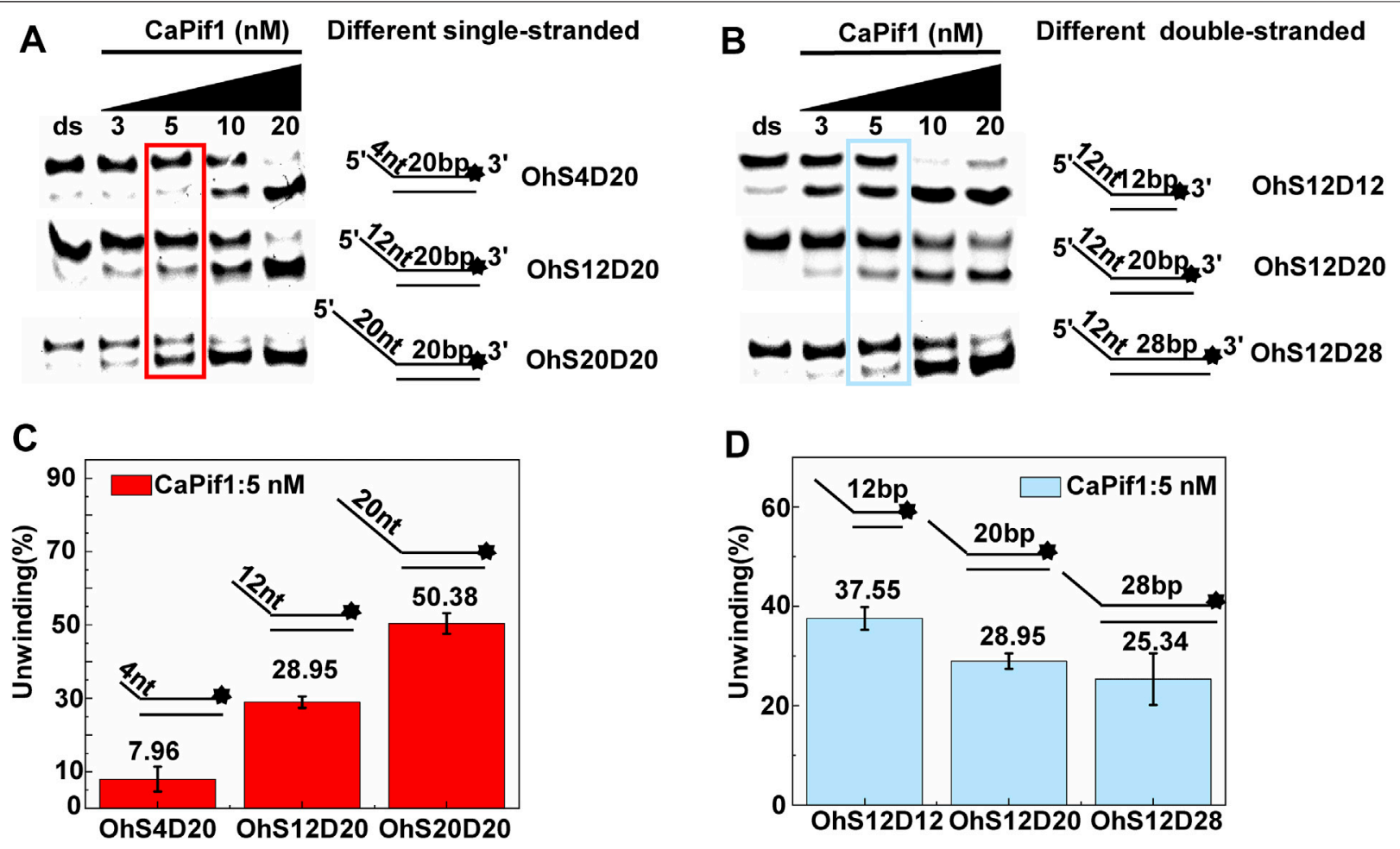

FIGURE 3 | Comparison of the unwinding activity of CaPif1 with DNA substrates with different lengths. (A) A series of 20-bp dsDNA substrates with varying lengths of the $5^{\prime}$-tailed duplex DNAs, from 4 to 20 nt. (B) The 12 nt tailed duplex DNAs with varying lengths of the duplex region (from 12 to 28 bp) (see Table 1 for substrate sequences). (C-D) The bar chart based on the unwinding ratio of at $5 \mathrm{nM}$ CaPif1 by scanning gray values with Image Lab software (Supplementary Table S2). All experiments were performed under standard experimental conditions as described in "Materials and Methods".

metal ions are important for maintaining the protein structure. However, some metal ions destroy the protein structure and cause proteins to lose helicase activity. To address the influence of the metallic cofactor, we further determined the unwinding activity in the presence of various metal ions. Both $\mathrm{Mg}^{2+}$ and $\mathrm{Mn}^{2+}$ had higher unwinding activities, and the results were relatively similar, while $\mathrm{Ca}^{2+}$ supported CaPifl to partially unwind the DNA duplex. In sharp contrast, in the presence of $\mathrm{Zn}^{2+}, \mathrm{Ni}^{2+}$, $\mathrm{Cu}^{2+}$, and $\mathrm{Cd}^{2+}$, this activity was completely lost at $1.5 \mathrm{mM}$ (Figure 5A). This showed that CaPif1 was unable to use these four ions to melt double-stranded DNA.

To determine if the unwinding activity of CaPif1 was inhibited by the four ions, we first studied the reactions containing both $\mathrm{Mg}^{2+}$ and one of the other metal ions. We found that when CaPif1 was incubated in advance with solutions containing $\mathrm{Zn}^{2+}, \mathrm{Ni}^{2+}$, or $\mathrm{Cd}^{2+}$, even with the addition of sufficient $\mathrm{Mg}^{2+}, \mathrm{CaPif} 1$ could not unwind the DNA duplex, while in a reaction containing $\mathrm{Cu}^{2+}$, with the addition of $\mathrm{Mg}^{2+}$, the unwinding activity of CaPif1 could be clearly observed. The results indicate that although CaPif1 cannot use $\mathrm{Cu}^{2+}$ to unwind dsDNA, $\mathrm{Cu}^{2+}$ does not inhibit the unwinding activity of CaPifl; however $\mathrm{Zn}^{2+}, \mathrm{Ni}^{2+}$, and $\mathrm{Cd}^{2+}$ have significant inhibitory effects on the unwinding activity of CaPif1 (Figure 5B). $\mathrm{Ni}^{2+}$ research showed the same result as $\mathrm{Cd}^{2+}$, and also demonstrated strong inhibition. However, in the reaction containing $\mathrm{Ni}^{2+}$, a brownish-yellow precipitation occurred that made it impossible for us to make an accurate quantitative analysis of the inhibition of the unwinding activity of CaPif1 by $\mathrm{Ni}^{2+}$ (Supplementary Table S4.1).

We have also adjusted the different addition order of $\mathrm{Zn}^{2+}$ / $\mathrm{Ni}^{2+} / \mathrm{Cd}^{2+}, \mathrm{Mg}^{2+}$, and CaPif1. Furthermore, regardless of whether $\mathrm{Zn}^{2+}, \mathrm{Ni}^{2+}$, or $\mathrm{Cd}^{2+}$ was added to reaction system first, or $\mathrm{Mg}^{2+}$ was added to reaction system first, or $\mathrm{Zn}^{2+} / \mathrm{Ni}^{2+} / \mathrm{Cd}^{2+}$ and $\mathrm{Mg}^{2+}$ were added at the same time, the inhibitory effects were similar for each heavy metal (Supplementary Table S4.2).

Next, we tested whether EDTA could restore the unwinding activity inhibited by $\mathrm{Cd}^{2+}$ and $\mathrm{Zn}^{2+}$. After the complete reaction of $1.5 \mathrm{mM} \mathrm{Zn}^{2+}$ or $\mathrm{Cd}^{2+}$ with $25 \mathrm{nM} \mathrm{CaPifl}$ at $30^{\circ} \mathrm{C}$ for $5 \mathrm{~min}$, we cleared the metal with $3 \mathrm{mM}$ EDTA (this concentration could completely remove the divalent metals in the mixture but was not sufficient to affect subsequent experiments), and then $1.5 \mathrm{mM} \mathrm{Mg}^{2+}$ and $5 \mathrm{mM}$ ATP were added to the mixture to initiate the spin reaction. The $\mathrm{Zn}^{2+}$ effect was abolished by adding EDTA (Figure 5C, lane 2 and lane 3), while the $\mathrm{Cd}^{2+}$ effect was not counteracted by EDTA (Figure 5C, lane 4 and lane 5). It is possible that $\mathrm{Cd}^{2+}$ can damage the active center of CaPif1 more severely at high concentrations $(1.5 \mathrm{mM})$, so that even after removing the ions, the unwinding activity of CaPifl cannot be restored. Further research showed that lower concentrations of $\mathrm{Zn}^{2+}$ and $\mathrm{Cd}^{2+}$ significantly inhibited the unwinding activity of CaPifl. When the concentrations of $\mathrm{Zn}^{2+}$ and $\mathrm{Cd}^{2+}$ were 100 and $10 \mu \mathrm{M}$, respectively, almost the same inhibitory effect was observed. $\mathrm{Cd}^{2+}$ showed stronger inhibition compared with 

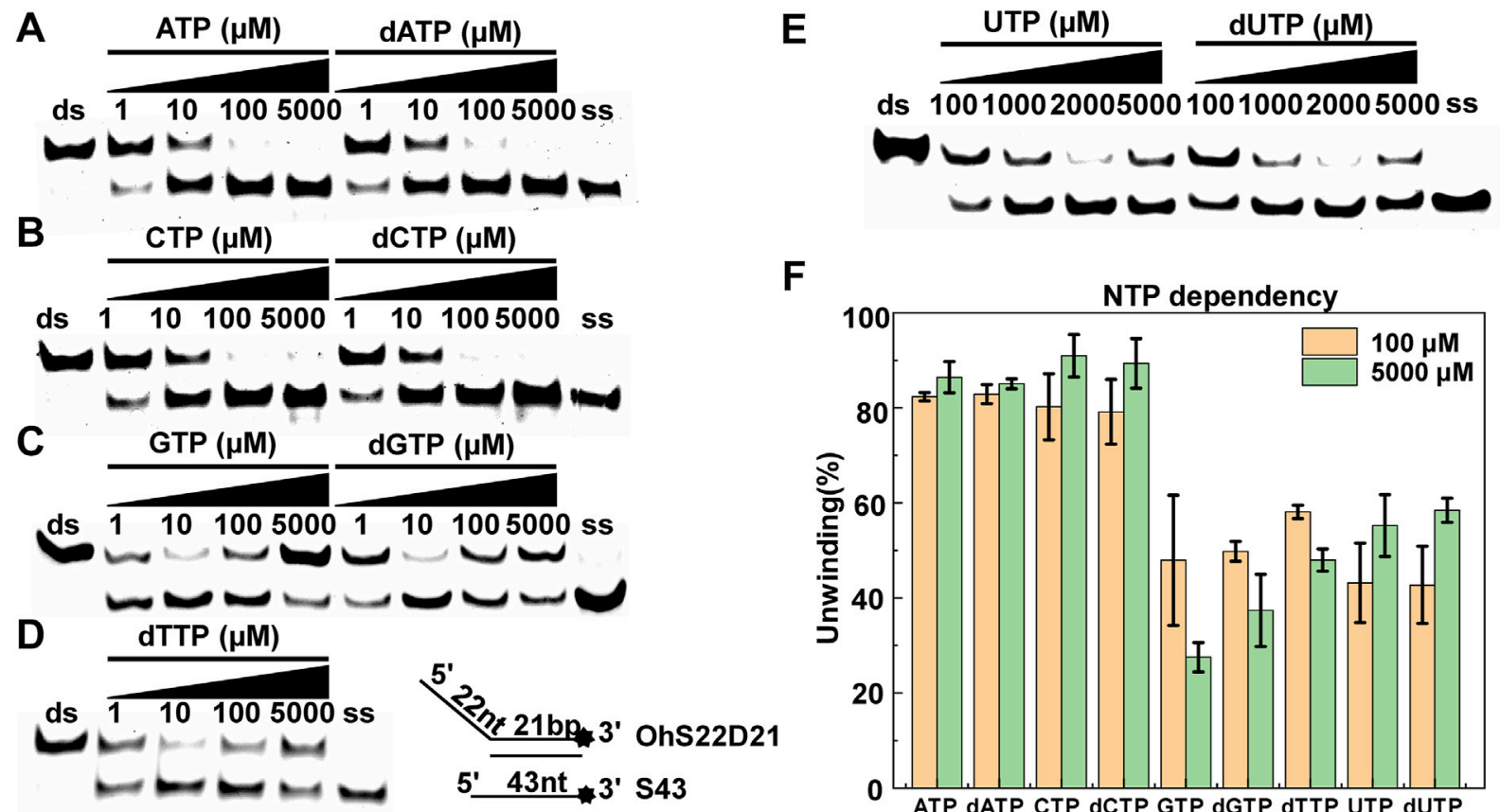

F

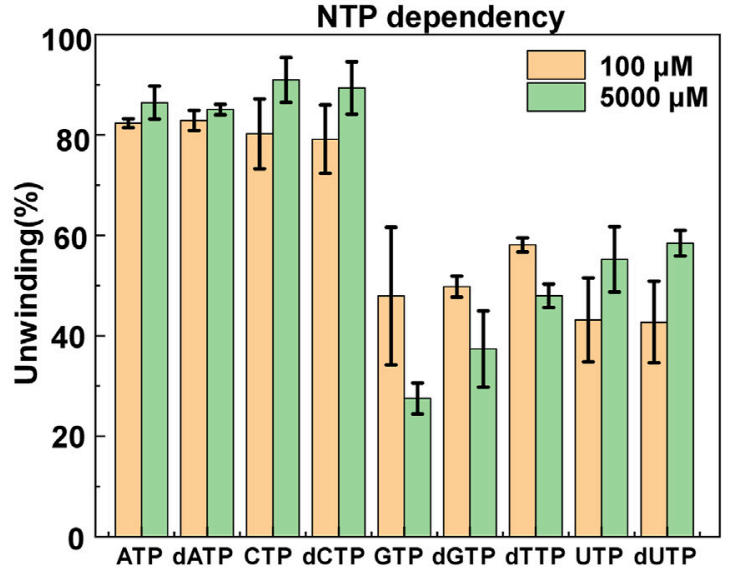

FIGURE 4 | NTP/dNTP preference of CaPif1. DNA was unwound in the presence of the indicated NTP or dNTP (A-E). The 5'-overhanged DNA substrate (OhS22D21) and CaPif1 concentrations were $25 \mathrm{nM}$, and the unwinding reaction was initiated with various NTP or dNTP concentrations. Lane ds: duplex DNA is not unwound, unwinding buffer (no ATP); Lane ss: single DNA with $3^{\prime}$-fluorescein ( $3^{\prime}$-FAM) (shown in Table 1). The numbers above the line indicate the concentrations of NTPs and dNTPs $(\mu \mathrm{M})$. (F) The proportion of unwinding DNA (Supplementary Table S3).

$\mathrm{Zn}^{2+}$, which was at a concentration 10 times lower than that of $\mathrm{Zn}^{2+}$ (Figure 5D).

In addition, we sought to examine whether the $\mathrm{Zn}^{2+}$ and $\mathrm{Cd}^{2+}$ could also inhibit the ATPase and DNA binding activities of CaPif1. Our data showed that whether the binding buffer contained $100 \mu \mathrm{M}$ of $\mathrm{Zn}^{2+}$ (or $\mathrm{Cd}^{2+}$ ) or not, the fluorescence anisotropy values were not significantly different (Figure 5E), indicating that $\mathrm{Zn}^{2+}$ and $\mathrm{Cd}^{2+}$ had no significant effect on the DNA binding activity of CaPif1. The ATP hydrolysis activity of CaPif1 was a function of ATPase, so the ATP concentration was detected before and after the reaction. The data showed that the ATPase activity containing $\mathrm{Zn}^{2+}$ and $\mathrm{Cd}^{2+}$ was significantly lower than that without $\mathrm{Zn}^{2+}$ and $\mathrm{Cd}^{2+}$ (Figures 5F,G). Further analysis revealed that when the concentration of $\mathrm{Cd}^{2+}$ reached $100 \mu \mathrm{M}$, the ATPase activity of CaPif1 was almost completely inhibited. Thus, we speculate that heavy metals inhibit the unwinding activity of CaPif1 by blocking its energy pathway.

\section{The Effects of Amino Acids and ATP on the $\mathrm{Zn}^{2+}\left(\mathrm{Cd}^{2+}\right)$ inhibition}

Although it was difficult to recover the effect of high concentration of $\mathrm{Cd}^{2+}$ on CaPif1, we found that when $\mathrm{Cd}^{2+}$ $(10 \mu \mathrm{M})$ and $\mathrm{Zn}^{2+}(70 \mu \mathrm{M})$ were at low concentrations (significantly inhibiting the unwinding of CaPif1), Cys and ATP could reduce this damage. Previous studies have reported that free sulfhydryl groups of Cys are good candidates for $\mathrm{Cd}^{2+}$ binding (Witkiewicz-Kucharczyk and Bal, 2006).
At the same time, Cys, histidine (His), valine (Val), and leucine (Leu) were also included to check their interaction with $\mathrm{Cd}^{2+}$ / $\mathrm{Zn}^{2+}$. They were incubated with unwinding buffer containing $\mathrm{Cd}^{2+}$ at $30^{\circ} \mathrm{C}$ for $5 \mathrm{~min}$. Then CaPifl was added and incubated at $30^{\circ} \mathrm{C}$ for another $5 \mathrm{~min}$, before ATP was added to start the reaction. We found that with increasing Cys concentrations, the inhibition of the unwinding activity of CaPifl by $\mathrm{Cd}^{2+}$ decreased significantly. This may have been due to Cys binding to the $\mathrm{Cd}^{2+}$ in the reaction, so the concentration of free $\mathrm{Cd}^{2+}$ was low, which reduced the damage to the activity of CaPif1 (Figure 6A). None of the four amino acids significantly alleviated damage in samples containing $\mathrm{Zn}^{2+}$ (Figure 6B).

We changed the order that samples were added in. For example, CaPif1 was first pre-incubated with the solution containing $10 \mu \mathrm{M} \mathrm{Cd}^{2+}$, and then $10 \mathrm{mM}$ Cys was added. This process still showed a reduction of the inhibition of CaPifl's unwinding activity by $\mathrm{Cd}^{2+}$ (Supplementary Table S5). This may imply that during the unwinding process of CaPif1, increasing the concentration of Cys to a certain level can prevent the inhibitory effect of $\mathrm{Cd}^{2+}$.

Finally, we increased the concentration of ATP to alleviate the inhibition of CaPifl's unwinding activity by low concentrations of $\mathrm{Zn}^{2+}$ and $\mathrm{Cd}^{2+}$. The two experiments showed different results. Increasing ATP concentration obviously reduced the inhibition of $\mathrm{Zn}^{2+}$, while $\mathrm{Cd}^{2+}$ did not resume the unwinding activity of CaPif1 to an obvious degree (Figure 6C). The possible reason may be that the CaPif1 unwinding activity is ATP-dependent. Therefore, increasing the ATP concentration within a certain 


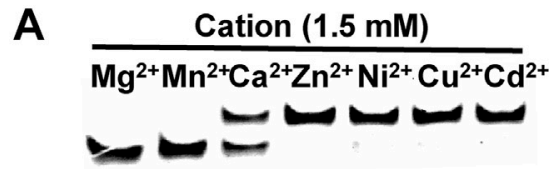

B

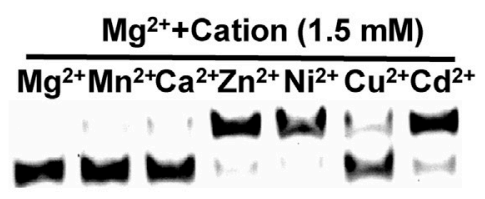

E

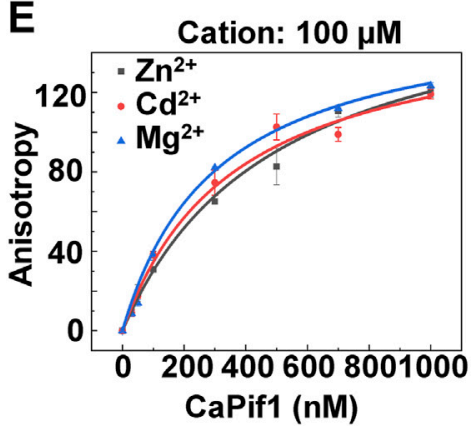

C

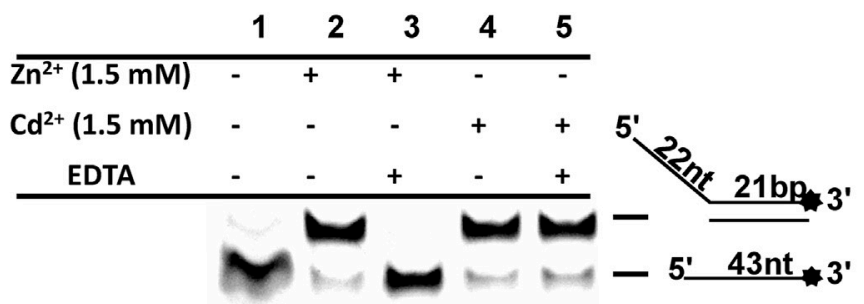

D

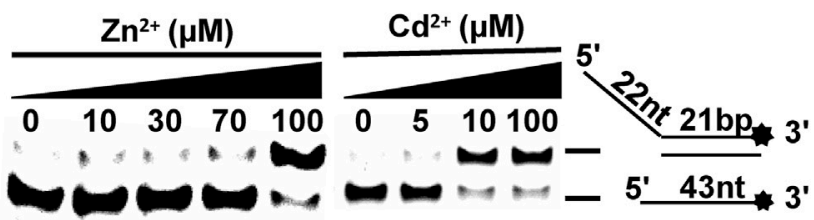

$\mathbf{F}$

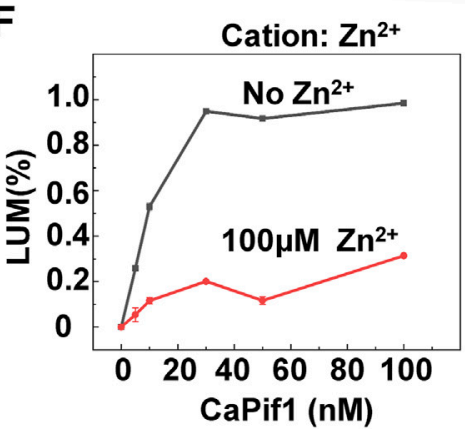

G

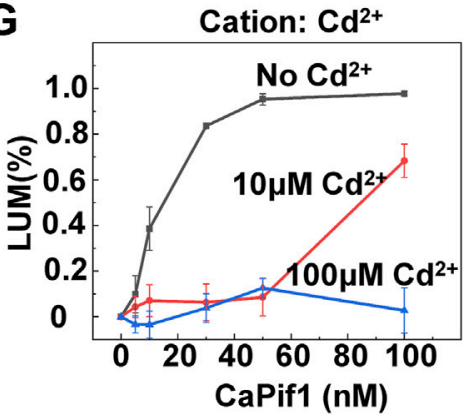

FIGURE 5 | The effects of metals on the unwinding activity of CaPif1. (A) CaPif1 (25 nM) was reacted with the DNA OhS22D21 (10 nM) in the presence of the indicated divalent metal (1.5 mM). (B) CaPif1 was incubated with indicated divalent metal $(1.5 \mathrm{mM})$ and then the same concentration of $\mathrm{MgCl}_{2}$ was added separately. (C) Lane 1: The control group containing $1.5 \mathrm{mM} \mathrm{Mg}^{2+}$ without $\mathrm{Zn}^{2+}$ and $\mathrm{Cd}^{2+}$; Lane 2 and Lane 4: same method (Figure 5B); Lane 3 and Lane 5: CaPif1 separately incubated with $\mathrm{Zn}^{2+}(1.5 \mathrm{mM})$ or $\mathrm{Cd}^{2+}(1.5 \mathrm{mM})$ at $30^{\circ} \mathrm{C}$ for $5 \mathrm{~min}$, then add $\mathrm{MgCl}_{2}$ with a final concentration of $1.5 \mathrm{mM}$, incubate again at the same temperature for $5 \mathrm{~min}$, and finally add the $5 \mathrm{mM}$ of ATP to start the unwinding reaction. (D) Inhibit the unwinding activity of CaPif1 at low concentrations $\mathrm{Zn}^{2+}$ or Cd ${ }^{2+}$. A total of $10 \mathrm{nM}$ of fluorescently labeled DNA substrate (OhS22D21) was titrated with increasing concentrations of $\mathrm{Zn}^{2+}$ or $\mathrm{Cd}^{2+}$. More details are described in the "Materials and Methods" section. (E) Polarized light is used to detect the influence of $\mathrm{Zn}^{2+}, \mathrm{Mg}^{2+}$, and $\mathrm{Cd}^{2+}$ on the binding activity of CaPif1, the ordinate is the anisotropy value, and the abscissa is the concentration of CaPif1. As detected by the Spectra Max iD3 microplate reader. (F-G) The influences of $\mathrm{Zn}^{2+}(\mathbf{F})$ or Cd ${ }^{2+}(\mathbf{G})$ on the ATPase. LUM (\%) is the percentage of ATP consumed (CaPif1 group the control group*100\%).

range can increase the activity of CaPif1, showing an apparent recovery of CaPif1 activity. The damage caused by $\mathrm{Cd}^{2+}$ is more serious than that caused by $\mathrm{Zn}^{2+}$, so it may not be able to offset this damage through the increase of ATP.

\section{The Effects of DTT on CaPif1 Unwinding Activity inhibited by $\mathrm{Zn}^{2+}$ and $\mathrm{Cd}^{2+}$}

DTT has been previously described having $\mathrm{Cd}^{2+}$-induced cell damage and enzyme inhibition (Stacey, 1986; Ahammadsahib et al., 1989). All the results mentioned above were obtained under reducing conditions (in the presence of DTT). We first fixed the concentration of CaPifl in the reaction without $\mathrm{Zn}^{2+}$ and $\mathrm{Cd}^{2+}$, and increased the concentration of DTT. The results showed that DTT had no effect on the unwinding activity of CaPif1 (Figure 7A). Then we compared the unwinding activity of CaPifl in the presence of $1.5 \mathrm{mM} \mathrm{Zn}^{2+}$ or $100 \mu \mathrm{M} \mathrm{Cd}^{2+}$ and gradually increased the concentration of DTT. In the reaction without DTT, neither $\mathrm{Zn}^{2+}$ nor $\mathrm{Cd}^{2+}$ could inhibit the unwinding activity of CaPif1 (Figures 7B,C). This implied that CaPif1 resisted the inhibitory effect of $\mathrm{Zn}^{2+}$ and $\mathrm{Cd}^{2+}$ in less reducing environments. We speculate that when there is a certain concentration of DTT in the environment, the disulfide bond of the protein is opened, thereby releasing more sulfhydryl groups on the surface of the protein, and $\mathrm{Zn}^{2+} / \mathrm{Cd}^{2+}$ can bind tightly to the sulfhydryl group of cysteine, resulting in more heavy metals destroying the activity of the protein. Interestingly, the reducing status in the body will decrease in the presence of $\mathrm{Cd}^{2+}$, which stimulates ROS production in the body (Srinivas et al., 2019). We speculate that CaPif1 has formed a mechanism to respond to heavy metal poisoning by effectively sensing the reducing status changes.

\section{DISCUSSION}

Cadmium is a recognized human and animal carcinogen. It can cause DNA damage directly by inhibiting the activity of DNArepair proteins and stimulating ROS production, thus reducing the status of the body (Hengstler et al., 2003). Zinc and cadmium have similar physical and chemical properties. Both are closely related to DNA-repair proteins. Pif1, a DNA-repair protein, acts 

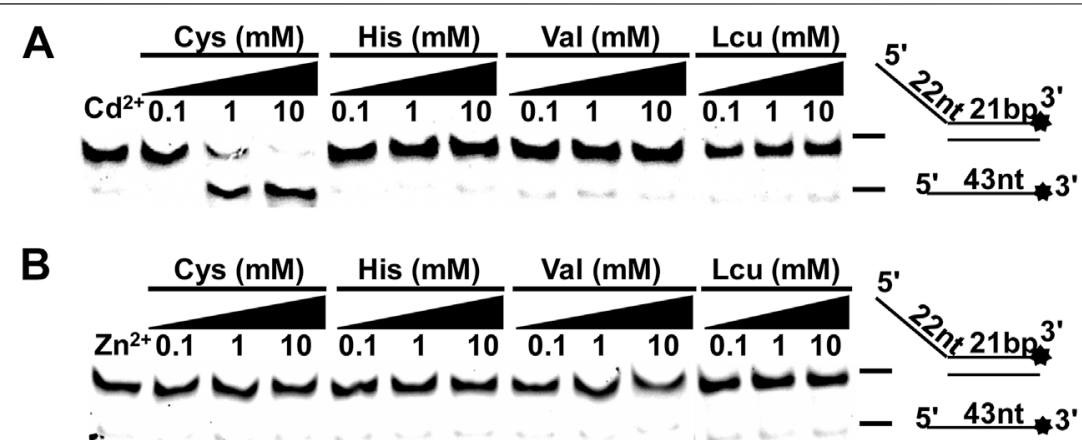

C $\operatorname{ATP}(\mathrm{mM}) ; \mathrm{Zn}^{2+}: 70 \mu \mathrm{M}$ ATP $(\mathrm{mM}) ; \mathrm{Cd}^{2+}: 10 \mu \mathrm{M}$

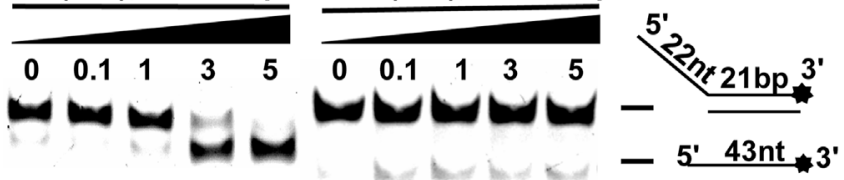

FIGURE 6| The effects of amino acids and ATP on the $\mathrm{Zn}^{2+}\left(\mathrm{Cd}^{2+}\right)$ inhibition. (A-B) CaPif1 (25 nM) was reacted with the DNA OhS22D21 (10 nM) in the presence of the indicated amino acids. Lane 1: The control group containing $\mathrm{Cd}^{2+}(10 \mu \mathrm{M})$ or $\mathrm{Zn}^{2+}(70 \mu \mathrm{M})$ without amino acid; 0.1 , 1 , and 10 represent the amino acid concentration $(\mathrm{mM})$. (C) In the reaction of lower concentrations of $\mathrm{Cd}^{2+}(10 \mu \mathrm{M})$ or $\mathrm{Zn}^{2+}(70 \mu \mathrm{M})$, the concentration of was increased ATP.

A

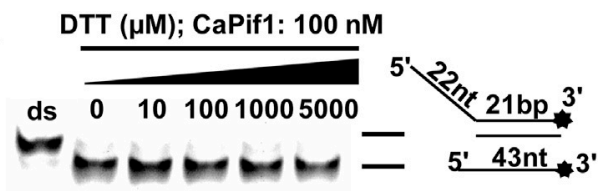

B DTT ( $\mu \mathrm{M}) ; \mathrm{Zn}^{2+}: 1.5 \mathrm{mM}$

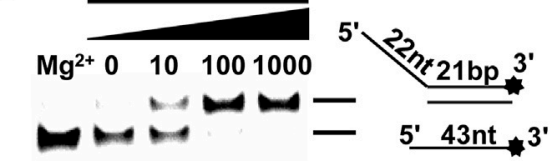

C DTT $(\mu \mathrm{M}) ; \mathrm{Cd}^{2+}: 100 \mu \mathrm{M}$

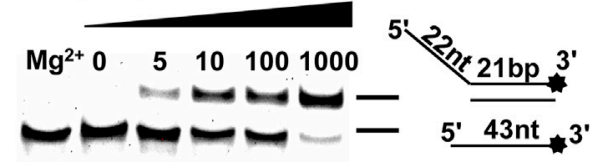

FIGURE 7 | The effects of DTT on CaPif1 unwinding activity inhibited by $\mathrm{Zn}^{2+}$ and $\mathrm{Cd}^{2+}$. (A) The unwinding activity of CaPif1 at different concentrations of DTT, containing only $\mathrm{MgCl}_{2}$, no other divalent metal ions. (B-C) The unwinding activity of CaPif1 at $1.5 \mathrm{mM} \mathrm{Zn}^{2+}$ or $100 \mu \mathrm{M} \mathrm{Cd}^{2+}$ and different concentrations of DTT. Lane $\mathrm{Mg}^{2+}:$ A standard unwinding experiment containing $\mathrm{MgCl}_{2}$ without $\mathrm{Zn}^{2+}$ or $\mathrm{Cd}^{2+}$.

at telomeres, rDNA, G-quadruplexes, R-loops, break-induced replication, and Okazaki fragment maturation (GarciaRodriguez et al., 2018). In this context, the study of heavy metal toxicity on Pif1 is of great significance to understand the mechanism of heavy metal toxicity and the role of Pif1 in maintaining genomic stability.
First, we reported the expression, purification, and biochemical analysis of CaPifl. It was confirmed that it had DNA binding, annealing, and ATP- and $\mathrm{Mg}^{2+}$-dependent $5^{\prime} \rightarrow 3^{\prime}$ direction helicase activity. CaPif1 can utilize the five types of NTP or dNTP, showing a preference for ATP and CTP; even a high concentration $(5 \mathrm{mM})$ of GTP, UTP, or dTTP can inhibit the unwinding activity. Pifl has been reported to efficiently unwind various structured DNA preferences to duplex DNA with $5^{\prime}$-overhangs (Liu et al., 2015). CaPifl prefers to unwind $5^{\prime}$-overhang DNA with long $5^{\prime}$-tail strands and a short duplex stranded region, indicating that the unwinding activity of CaPif1 has a certain persistence.

Second, the effects of six heavy metals $(\mathrm{Mn}, \mathrm{Ca}, \mathrm{Zn}, \mathrm{Ni}, \mathrm{Cu}$, and $\mathrm{Cd})$ on the unwinding activity of CaPifl were detected. The presence of $\mathrm{Mn}^{2+}$ or $\mathrm{Ca}^{2+}$ can also replace $\mathrm{Mg}^{2+}$ and support the CaPif1driven unwinding of $5^{\prime}$-overhang DNA. Notably, $\mathrm{Zn}^{2+}$ and $\mathrm{Cd}^{2+}$ cannot support it and inhibit the unwinding activity and ATPase of CaPifl but have no effects on DNA binding activity. The inhibitory effect of $\mathrm{Zn}^{2+}$ at $100 \mu \mathrm{M}\left(\mathrm{Cd}^{2+}\right.$ at $\left.10 \mu \mathrm{M}\right)$ was more than $70 \%$, and $\mathrm{Cd}^{2+}$ was 10 times stronger than $\mathrm{Zn}^{2+}$. Free cysteine protects the unwinding activity of the enzyme from $\mathrm{Cd}^{2+}$, indicating that $\mathrm{Cd}^{2+}$ dependent unwinding activity effect may be associated with the cysteine residues of CaPif1. EDTA could not reverse high concentration of $\mathrm{Cd}^{2+}$ inhibition, which suggests that high concentration of $\mathrm{Cd}^{2+}$ causes irreversible changes in the protein structure. In contrast, the inhibition of $\mathrm{Zn}^{2+}$ can be reversed by EDTA and can be mitigated by adding ATP, thus showing that $\mathrm{Cd}^{2+}$ is more destructive. $\mathrm{Zn}^{2+}$ has been previously reported to inhibit cadmium toxicity (Qin et al., 2016). This is similar to our experimental results. With the same inhibitory effect, the concentration of $\mathrm{Zn}^{2+}$ is nearly 10 times higher than that of $\mathrm{Cd}^{2+}$.

Finally, we found an interesting phenomenon: $\mathrm{Cd}^{2+}$ and $\mathrm{Zn}^{2+}$ could not significantly inhibit the unwinding activity of CaPif1 
under non-reducing conditions, and the inhibition was proportional to the degree of reduction. Since it was previously shown that the reducing environment of the body decrease in the presence of $\mathrm{Cd}^{2+}$, as the metal stimulated an increase of ROS in the body, CaPifl may resist cadmium poisoning by monitoring the reducing status of the body. This may be an ancient mechanism for organisms to adapt to heavy metal stress.

Collectively, we report the functions of CaPif1 and the toxicity mechanism of $\mathrm{Zn}^{2+}$ and $\mathrm{Cd}^{2+}$ to CaPif1. This work provides new clues to help us better understand the toxicological mechanism of heavy metal toxicity.

\section{DATA AVAILABILITY STATEMENT}

The original contributions presented in the study are included in the article/Supplementary Material, further inquiries can be directed to the corresponding authors.

\section{REFERENCES}

Ahammadsahib, K., Jinna, R., and Desaiah, D. (1989). Protection against Cadmium Toxicity and Enzyme Inhibition by Dithiothreitol. Cel Biochem. Funct. 7 (3), 185-192. doi:10.1002/cbf.290070306

Andreini, C., Bertini, I., and Rosato, A. (2004). A Hint to Search for Metalloproteins in Gene banks. Bioinformatics 20 (9), 1373-1380. doi:10.1093/bioinformatics/bth095

Boule, J. B., Vega, L. R., and Zakian, V. A. (2005). The Yeast Piflp Helicase Removes Telomerase from Telomeric DNA. Nature 438 (7064), 57-61. doi:10.1038/nature04091

Brzoska, M. M. (2001). Interactions between Cadmium and Zinc in the Organism. Food Chem. Toxicol. 39 (10), 967-980. doi:10.1016/s02786915(01)00048-5

Chen, B., Hua, Z., Gong, B., Tan, X., Zhang, S., Li, Q., et al. (2020). Downregulation of PIF1, a Potential New Target of MYCN, Induces Apoptosis and Inhibits Cell Migration in Neuroblastoma Cells. Life Sci. 256, 117820. doi:10.1016/ j.lfs.2020.117820

Choudhary, S., Sommers, J. A., and Brosh, R. M., Jr. (2004). Biochemical and Kinetic Characterization of the DNA Helicase and Exonuclease Activities of Werner Syndrome Protein. J. Biol. Chem. 279 (33), 34603-34613. doi:10.1074/ jbc.M401901200

Frick, D. N., Banik, S., and Rypma, R. S. (2007). Role of Divalent Metal Cations in ATP Hydrolysis Catalyzed by the Hepatitis C Virus NS3 Helicase: Magnesium Provides a Bridge for ATP to Fuel Unwinding. J. Mol. Biol. 365 (4), 1017-1032. doi:10.1016/j.jmb.2006.10.023

Futami, K., Shimamoto, A., and Furuichi, Y. (2007). Mitochondrial and Nuclear Localization of Human Pifl Helicase. Biol. Pharm. Bull. 30 (9), 1685-1692. doi:10.1248/bpb.30.1685

Garcia-Rodriguez, N., Wong, R. P., and Ulrich, H. D. (2018). The Helicase Pif1 Functions in the Template Switching Pathway of DNA Damage Bypass. Nucleic Acids Res. 46 (16), 8347-8356. doi:10.1093/ nar/gky648

Geronimo, C. L., Singh, S. P., Galletto, R., and Zakian, V. A. (2018). The Signature Motif of the Saccharomyces cerevisiae Pif1 DNA Helicase Is Essential In Vivo for Mitochondrial and Nuclear Functions and In Vitro for ATPase Activity. Nucleic Acids Res. 46 (16), 8357-8370. doi:10.1093/nar/ gky655

Harmon, F. G., and Kowalczykowski, S. C. (2001). Biochemical Characterization of the DNA Helicase Activity of the escherichia Coli RecQ Helicase. J. Biol. Chem. 276 (1), 232-243. doi:10.1074/ jbc.M006555200

\section{AUTHOR CONTRIBUTIONS}

YL, YX, and BZ wrote the article and drew the figures. BZ, QZ, $\mathrm{YX}, \mathrm{XZ}, \mathrm{DL}, \mathrm{XD}, \mathrm{JJ}$, and $\mathrm{KW}$ edited the article.

\section{FUNDING}

This research was funded by the Guizhou Province Science and Technology Department (2020)1Y151, the National Natural Science Foundation of China (31860315), and the Doctor Research Foundation of Zunyi Medical College (F-939).

\section{SUPPLEMENTARY MATERIAL}

The Supplementary Material for this article can be found online at: https://www.frontiersin.org/articles/10.3389/fmolb.2021.778647/ full\#supplementary-material

Hengstler, J. G., Ulrich, B. A., Andreas, F., Kai, J., Michael, R., Walter, G., et al. (2003). Occupational Exposure to Heavy Metals: DNA Damage Induction and DNA Repair Inhibition Prove Co-exposures to Cadmium, Cobalt and lead as More Dangerous Than Hitherto Expected. Carcinogenesis 1, 63-73. doi:10.1093/carcin/ 24.1.63

Ivessa, A. S., Zhou, J.-Q., and Zakian, V. A. (2000). The Saccharomyces Piflp DNA Helicase and the Highly Related Rrm3p Have Opposite Effects on Replication Fork Progression in Ribosomal DNA. Cell 100 (4), 479-489. doi:10.1016/s00928674(00)80683-2

Jomova, K., and Valko, M. (2011). Advances in Metal-Induced Oxidative Stress and Human Disease. Toxicology 283 (2-3), 65-87. doi:10.1016/ j.tox.2011.03.001

Liu, N. N., Duan, X. L., Ai, X., Yang, Y. T., Li, M., Dou, S. X., et al. (2015). The Bacteroides Sp. 3_1_23 Pif1 Protein Is a Multifunctional Helicase. Nucleic Acids Res. 43 (18), 8942-8954. doi:10.1093/nar/gkv916

Maret, W., and Moulis, J. M. (2013). The Bioinorganic Chemistry of Cadmium in the Context of its Toxicity. Met. Ions Life Sci. 11, 1-29. doi:10.1007/978-94-0075179-8_1

Qin, W., Bazeille, N., Henry, E., Zhang, B., Deprez, E., and Xi, X. G. (2016). Mechanistic Insight into Cadmium-Induced Inactivation of the Bloom Protein. Sci. Rep. 6, 26225. doi:10.1038/srep26225

Srinivas, U. S., Tan, B. W. Q., Vellayappan, B. A., and Jeyasekharan, A. D. (2019). ROS and the DNA Damage Response in Cancer. Redox Biol. 25, 101084. doi:10.1016/j.redox.2018.101084

Stacey, N. (1986). Protective Effects of Dithiothreitol on Cadmium-Induced Injury in Isolated Rat Hepatocytes. Toxicol. Appl. Pharmacol. 82 (2), 224-232. doi:10.1016/0041-008x(86)90197-3

Waisberg, M., Joseph, P., Hale, B., and Beyersmann, D. (2003). Molecular and Cellular Mechanisms of Cadmium Carcinogenesis. Toxicology 192 (2-3), 95-117. doi:10.1016/s0300-483x(03)00305-6

Wang, J., Zhu, X., Ying, P., and Zhu, Y. (2020). PIF1 Affects the Proliferation and Apoptosis of Cervical Cancer Cells by Influencing TERT. Cancer Manag. Res. 12, 7827-7835. doi:10.2147/ CMAR.S265336

Witkiewicz-Kucharczyk, A., and Bal, W. (2006). Damage of Zinc Fingers in DNA Repair Proteins, a Novel Molecular Mechanism in Carcinogenesis. Toxicol. Lett. 162 (1), 29-42. doi:10.1016/ j.toxlet.2005.10.018

Yildiz, A., Kaya, Y., and Tanriverdi, O. (2019). Effect of the Interaction between Selenium and Zinc on DNA Repair in Association with Cancer Prevention. J. Cancer Prev. 24 (3), 146-154. doi:10.15430/ JCP.2019.24.3.146 
Yu, H. T., Zhen, J., Leng, J. Y., Cai, L., Ji, H. L., and Keller, B. B. (2021). Zinc as a Countermeasure for Cadmium Toxicity. Acta Pharmacol. Sin 42 (3), 340-346. doi:10.1038/s41401-020-0396-4

Zhang, B., Wu, W. Q., Liu, N. N., Duan, X. L., Li, M., Dou, S. X., et al. (2016). G-quadruplex and G-Rich Sequence Stimulate Piflp-Catalyzed Downstream Duplex DNA Unwinding through Reducing Waiting Time at ss/dsDNA junction. Nucleic Acids Res. 44 (17), 8385-8394. doi:10.1093/nar/gkw669

Conflict of Interest: The authors declare that the research was conducted in the absence of any commercial or financial relationships that could be construed as a potential conflict of interest.
Publisher's Note: All claims expressed in this article are solely those of the authors and do not necessarily represent those of their affiliated organizations, or those of the publisher, the editors, and the reviewers. Any product that may be evaluated in this article, or claim that may be made by its manufacturer, is not guaranteed or endorsed by the publisher.

Copyright $\odot 2022$ Zhang, Zhang, Zhu, Li, Duan, Jin, Wang, Xie and Liu. This is an open-access article distributed under the terms of the Creative Commons Attribution License (CC BY). The use, distribution or reproduction in other forums is permitted, provided the original author(s) and the copyright owner(s) are credited and that the original publication in this journal is cited, in accordance with accepted academic practice. No use, distribution or reproduction is permitted which does not comply with these terms. 